\title{
Yoruba Indigenous Medicine in Search of Justification
}

\author{
Richard Taye Oyelakin \\ Department of Philosophy \\ Obafemi Awolowo University \\ Ile-Ife \\ Nigeria \\ richyman2009@yahoo.com \\ oyelakin@oauife.edu.ng
}

\begin{abstract}
Yoruba Indigenous Medicine (YIM) faces the question of empirical justification. This presents a satisfying conditions of the scientific requirements for its significance and recognition.. YIM is questioned for lack of empirical justification whereas Orthodox Medicine (OM) takes pride in being justified. This paper argues that if being justified is being empirically verifiable, then science, which is the foundation for OM, is also ultimately unjustified. If YIM is magical because it is not empirically justifiable then OM suffers the same fate. However, the paper further argues that if being justified is defined by being efficacious, then YIM is as justified as OM. The paper intends to show that science is ultimately empirically unjustified. Showing this disqualifies OM from alleging YIM as empirically unjustified. The paper concludes that in matter of empirical justification, both YIM and OM fall whereas in matter of efficacy they stand. Employing philosophical means, the paper holds that YIM shares the same lot with OM. Therefore, OM lacks sufficient grounds to declare YIM as unjustified.
\end{abstract}

\section{Introduction}

Yoruba Indigenous Medicine, (henceforth YIM) has been struggling with the demand for empirical evidence. Some African scholars have attempted to explain this phenomenon in a way to make it amenable to requirements and 
formulations of empirical science. In some cases, these attempts have seen the rudiments of YIM mutilated to the point of giving up some necessary aspect. All these are done to grant it a stand in the arena of empirical science. However, these attempts have proved inadequate. This is because an account or conceptual interpretation or re-interpretation, as it were, that could make the core of YIM empirically justifiable might be difficult to develop. However, this is not a minus for it.

It is a truism that Orthodox Medicine (henceforth OM) subsists on the foundation of empirical science. It shall be proved that both OM and YIM are fundamentally unjustifiable by empirical procedure. Therefore, it shall be argued that if being magical means unscientifically justified, then both OM and YIM are presumably magical. The position defended is that whereas YIM is labelled unjustified and then magical since it fails the test of empirical justification, western science also does not, ultimately pass the test. If OM is built on the foundation of western science, then it also faces the problem. However, if $\mathrm{OM}$ is recognized and accepted based on its efficacious evidences and results, such evidences and results abound showing the efficacy of YIM. The paper concludes that the condemnation of YIM on the basis of insufficient empirical justification is rather too exclusive.

\section{YIM and the Challenge of Justification}

Contrary to some popular suggestions such as Olson and Nkiwane (2006), Oyelakin (2009) rather called for an independent development of the Yoruba traditional medicine. This is to enable its acceptability which is necessary for its efficacy; not only for the Yoruba people but humanity at large. This call was made on the grounds that the suggested integration between Yoruba traditional medicine and $\mathrm{OM}$ is unnecessary. However, this does not downplay their complementary relationship. Parallel to OM, it is possible that YIM could be strongly developed to be recognized and serve humanity in more significant ways. Expectedly, for any phenomenon to attain the position of serving humanity in the capacity of healing and health restoration, it is expected that such a phenomenon must be scientifically/empirically justified. But, it is observed that when YIM faces the question of empirical justification, the account breaks down. This largely accounts for its questionable nature.

However, though Kola Abimbola (2006) referred to the OM as allopathic in nature, it is mainly accepted on the basis of the possibility of its empirical justification. What this means is that the phenomenon is capable of being subjected to empirical investigation, and scientific experimentation. The success of the phenomenon explains the empirical certainty that the process which produces the drugs and medications is experimentally testable, repeatable and 
eventually predictable. What this suggests is that the process of drug or medicine production is not spatiotemporally restricted to locations and or individuals. The systematic and empirical procedures which produce the medication, are laid out. By being laid out, it means that the process can be objectively followed and tested in any available location with the expectation of similar results. This guarantees the possibility that the process can be repeated and result predicted. Thus, the Phenomenon passes the test of emperical objectivity and then scientific justification.

The process which produces YIM, allegedly, does not pass this test. For instance, the process which produces a medication to cure vocal epilepsy; (wárápá), is not completely objective. In most cases, Yoruba people believed that such illness is not ordinary or natural. It is believed to ní owwo ayé nínú, i.e. that a person could only be afflicted with the sickness by some evil forces. As the cause is believed to be supernatural, it is expected that extra-ordinary means should be used to address extra-ordinary illness. This extra-ordinary means is supposedly not empirical in nature. Then, not all the necessary ingredients could be laid out for empirical investigation because not all are empirical. The medication must include some non-empirical process such as, invocations and sacrifices, as well as ìpèsè / ẹbẹ to appease the forces.

Nonetheless, an instructive and very crucial distinction, which is of benefit to many scholars and researchers must be made here. YIM consists of two main aspects: empirical and metaphysical (non-empirical maybe spiritual) aspects, (Makinde 2007: 374, Awojoodu \& Baran 2009: 130, Abdulahi 2011). The first aspect deals with herbs and herbal medicine. The second involves sacrifice and invocation of spirits and incantation, which is used to lay claims and then command the forces of nature for intervention and accomplishment in relevantly peculiar cases. This aspect of YIM is situated within the realm Yoruba religious belief system, (Mbiti 1969: 2-3, Awolalu 1979: 74) which Awolalu (1979: 75) described as exoteric. Correspondingly, there are specialists in each aspect. Those who specialize on the herb and herbal medicine are referred to as onísègùn (herbalist), while Babaláwo (Ifa Priest) specializes on the second aspect. Herbal aspect of YIM, presumably and to a large extent, raises no problem concerning justification. This is because herbalism is ultimately empirical in nature. Medicine or drug which is produced from herbs is largely subject to empirical test or laboratory investigation. The chemical contents of the leaves and herbs used by onisèegùn (herbalist) are subjectable to scientific scrutiny, at least, in principle. This is evidenced by the testimony of Borokini and Lawal (2014: 29), about the modernization of Traditional medicine in Nigeria. The process of extracting contents from "bitter leaves" (ewé ewúro) is neither unintelligible nor magical, whatever healing work it performs. This 
process and its efficacy is repeatable and predictable. This, again, satisfies the criteria of scientific phenomenon and could be empirically justified.

Culturally however, herbalism is not completely independent of non-physical aspect of YIM as presumed. Though herbalism deals mainly with empirical part of plants, it is also tied to its patron divinity which is called Osanyìn, who is believed to understand the healing properties embedded in various plants. (Awolalu 1979: 74, Adekola 1998: 180, Oduyoye 1983: 168, Jegede 2010: 14). Based upon this belief, when a herbalist goes to collect the herbs, "he has to utter incantations as he digs for roots and picks leaves," (Awolalu 1979: 73). Two variants of herbalism emerge. To the extent that herbalism is identified with Osanyìn it has assumed the second aspect, without such assumption, it is empirical and in principle subject to empirical investigation and then justification.

However, the second aspect of YIM, as it were, raises a problem of justification. This is identified by Makinde as "the dispute is more on the side of one aspect of traditional medicine usually referred to as magical than on the herbal medicine which is always open to empirical investigation and rigorous tests", (Makinde 1988: 91). However, Makinde identifies this aspect of the medicine as the most powerful (Ibid: 92). Regrettably, the more powerful aspect of YIM is labelled unjustified and then magical, at least, from the scientific point of view. It does appear that the conclusion is premature. The so-called magical aspect of YIM is only crying for attention and not condemnation. What appears as the main issue is how to make this phenomenon scientifically understandable: where "science" is understood as "empirical investigation." Judgement comes only when a phenomenon is sufficiently understood.

The problem which confronts YIM is now clear. Precisely, the main problem is not about herbalism. Herbalism is less problematic because it is, in principle, verifiable by scientific and empirical investigation. Therefore, the question of justification of herbalism is resolvable in principle. The core and the more important aspect of the YIM is that which involves incantation, commanding a phenomenon through the nature and powers of the ingredients involved in the medicine, sacrifice, ètùtù or ẹbe, spirits invocation, understanding and communicating with the invisible realities, and so on. Awolalu (1979: 75) described it as esoteric in the sense that it is limited only to those who have the knowledge. Makinde captures this more precisely as "Ifá divination and oral incantation" (Makinde 1988: 92). Jegede (2010: 14) outlines the medical roles, therapeutic relevance, and divinatory importance of Ifa. This is the aspect which obviously faces the question of justification. For Makinde, that which is referred to as magical is notably encapsulated in Ifá divination and oral incantation. 
Therefore, herbalism might be observed as an undeveloped level of orthodox medicine. However, it must be noted that herbs and herbal medicine prepared by an onișègùn, in some necessary cases, requires Babaláwo to authorize its efficacy. A Babaláwo might also require some herbs from an oniśègùn, as occasion demands. This explains the synergy and interdependence between the two, probably, different but complementary aspects of YIM. This is because "Ifá and Ọsanyìn therefore work together in the same way as doctors and chemists", (Jegede 2010: 15). However, Babaláwo (Ifá Priest) is considered more dominant in health and healing matters. Jegede's view shared from Abimbola (1983: 1) is that "Ifa priests are the physicians and the chemists in Yoruba communities. Ifa combines incantations with organic preparations, which are either made by the priest or his clients based on his directions ... hence the name aṣawo-șè-șègùn (a diviner and healer)" (Jegede 2010: 14 -15).

That the magical aspect of YIM remains unexplainable by scientific procedure and description there can be no doubt. This is because it is yet unclear how sacrifice, invocation of spirits, etc., and their acclaimed efficacy could be reduced to and explained in the language of empirical science. However, the puzzling question is, does it follow that since the so-called magical aspect of YIM is unexplainable and unjustified by empirical science, it is not justified? It is necessary to do a brief discussion on the question of justification.

\section{Does Empirical Science Satisfy the Demand of Empirical Justification?}

This section only intends to show that scientific phenomenon also faces the same question of justification at its fundamental level. This shows that science is itself fundamentally unintelligible and then magical, if unintelligible and magical means not empirically verifiable. This section will not enter into a deep discussion on justification. This is because the question of justification remains a perennial question in epistemology. Some of the questions raised include; what does it mean for a phenomenon to be justified? Could there be a conclusively justified phenomenon or system? If there could be, how can this be accounted for? For instance, a phenomenon or system is conclusive when it is technically certain. (Hamlyn 1970:10 -11). Technical certainty refers to a phenomenon or system, which in itself, is consistent and whose propositions express indubitable and infallible truth. Of course, this question constitutes the core of the charge of the skepticism against the possibility of knowledge. What this section intends to point out is that basically, as there are two main sources of knowledge identified by scholars, (Descartes 1680, Hume 1910, Kant 1963), there are, mainly, two available means of justification. A particular corpus of knowledge is either acquired from reason or experience (Hume 
1965: 323). Similarly, all the theories concerning justification could largely be encapsulated into two means. It is either a justification a priori or through experience. There you have the isms in place. Foundationalism, reliability, and fallibilism, are a priori attempts to prove that a true proposition is justified. Positivism, verification, reductionism, and naturalism, are appeals to show the strength of experience in determining that a particular true proposition is justified and are epistemically acceptable. However, attempts to understand what truth is raises correspondence and coherence theories of truth, (Hospers 1967: $114-22)$. These two are the main theories which specify the criteria of truth. Pragmatic criterion is ultimately an extension of correspondence theory.

Reason as means of justification is weakened by David Hume. For him, "all our ideas or more feeble perceptions are copies of our impressions or more lively ones", (Hume 1910). This means that the operation of reason ultimately depends on impression from experience acquired through the senses. This is, largely, strengthened by Locke's view that the mind is devoid of any idea at birth. "Let us then suppose the mind to be, as we say, white paper, void of all characters, without any ideas", (Locke 1690: 117). This position has some strength in the sense that it is undeniable that there is no ingenuity which can furnish one's mind with a color one has not yet perceived. Secondary colors are composite of the primary ones. One's knowledge of color and consequent inferences from them are strictly limited to empirical data already perceived. It could be concluded that the knowledge of the world is limited to the extent of ones' perception of it. The faculty of understanding only works on the acquired information in form of sensory impression, (Hume 1910, Kant 1963).

Arguing from the point of view of Locke and Hume, the justification of knowledge and truth is to be sought in experience. This shall be upheld on the condition that homo- sapiens are part of the structural properties of nature. If by nature we mean all and only the physic-material properties, then to justify knowledge we shall ultimately rely on experience. Arguing, as idealist realist, that there are immaterial properties existing in nature shall raise an epistemic demand, as Hume (1965) did, of how such properties is understood or known.

The next is to argue that experience which is established as the foundational justification of all the knowledge of the world is empirically unjustified. We shall, first, argue in agreement with Hume (1965) that the foundation of experience is in cause and effect. According to Hume (1910), ultimately, the idea of necessary connection must be established for cause and effect to the justified. For him, however, neither experience nor reason is sufficient to justify this idea. Therefore, empirical knowledge of the world is unjustified. By implication, the problem equally bedevils induction, causation, set theory, and etc... (Flanagan 1982: 67 -68), all of which are the pillars of scientific structure. Second, neutrons, protons, and muons are identified as the lowest 
divisible constituent of matter. It means that the existence of these must be empirically justified for matter to be justified. In other words, matter is not justified until these constituents are empirically justifiable. To argue that they are justified in so far as matter is justified is obviously fallacious. To justify these constituents, we must appeal to some further constituents. These further constituents must also require other constituents for their empirical justification. However, the question need not terminate at any particular point. A regress is obviously the outcome of such reasoning.

In principle, this is a problem for empirical science. To address the regress, something has to be justified. Conversely, science has not been able to provide such an ultimate empirical justification for this systematic constituents of matter. Apparently, without this justification, scientific phenomenon remains unjustified. It appears that something fundamental to the whole scientific system remains unjustified. This is the point which is established in Gödel's incompleteness theorem. It states that for scientific system to be consistent, there must be some propositions whose truths could not be proved by the principles operating within that scientific system, (Buechner 2008: 8). In fact, this affects both reason and experience as means of justification. At each point of the investigation, something must remain unjustified and then unintelligible for systematic understanding of nature to make any natural sense. However, to make a rational sense is to, agnostically, suspend ones judgement. But, doing this is anti-science and anti-development. What is now obvious is that orthodox medicine really thrives upon its effective and efficacious results, even though, arguably, its foundation appears empirically unjustifiable. There may be a sense in the claim that the foundation of science is not scientific. In other words, to be empirically unjustified is not synonymous with being unintelligible, otherwise science would be unintelligible.

\section{Justification by Efficacy: is YIM Justified?}

The point we have tried to establish is that on the question of empirical justification, what is true of YIM is also true of OM. Empirically speaking, both of them stand on an unjustified and then unintelligible foundation. The point to be established here is that should OM be justified by its efficacious strength, the same is true of YIM. There is no doubt that OM is efficacious and serving in health restoration. This is explained by its wide acceptance and general recognition. But, is YIM's efficacy in doubt? One of the evidences of the efficacy of YIM contains in the testimony of Dr. Stephen Farrow, as presented in Makinde's work, (Makinde 1988: 96 -97), whose “...veil of ignorance having been torn into shreds by his own bitter experience" (Ibid). Besides, Abdulahi (2011) and Jegede (2016) also document some efficacious results and notable 
advantages of the indigenous medicine. Obviously, evidences abound to testify to the efficacy of YIM. Such evidences are commonly found in the culture where this medicine is mainly practiced.

What this discourse is trying to establish is that whatever reason one identifies for preferring OM to its indigenous counterpart could always be presented with a stronger reason for preferring the indigenous medicine to its orthodox counterpart. This point is further accentuated by Makinde, "Although scientist may argue that it is pretty obvious that there are good scientific reasons for preferring science to magic, presumably, there would be good magical reasons for preferring magic to science in certain cases and circumstances." (Makinde 1988: 92). This point strengthens the reason why Makinde (1988: 97), Parrinder (1969: 157) and Lambo (1979: 23) refer to YIM as 'science.'

Furthermore, in matters of principle guiding the operation of a system, each body of enquiry has its own conventionally set principles. By 'convention' I mean pragmatic rules and principles which are acceptable because of their utility. One fundamental conventional principle guiding empirical science is verification. This means that each step in the process is capable of being empirically and objectively verified. But, YIM is not deficient on this. One of the conventional principles of the Yoruba science is the readiness to be surrendered for initiation in order to acquire the depth of the fundamental and systematic knowledge of the science. In most cases, this is one of the further extents which scholars and or OM experts are unwilling to proceed. But the principle is that without getting into the caucus of the initiated, it is impossible to acquire some certain restricted and preserved truths about the nature of the science. This is substantiated by Borokini and Lawal: "Given the fact that many of the TMPs are or were once in occultist groups, they gained access to much fundamental natural knowledge that eluded the imagination of an ordinary man," (Borokini \& Lawal 2014: 21).

The term 'occultic' here appears to depict evil, danger, and or wickedness. This has to be defused as this may label YIM as evil and wicked. The term 'occultic' is not necessarily conceived in its esoteric (Awolalu 1979: 75) sense and or synonymous with evil or wickedness. Rather in the view of Ilesanmi (2004: 08), it is used to "mean a specialized knowledge reserved for a certain group of people." This may also depict a group of individuals who have had access into a deeper but more classified realm of realities. However, this realm is not "a place of unreality or another reality; it is a subtle aspect of our everyday - every moment reality", (Grotte, 2016: 01). No one gains the knowledge of this reality until initiated. When initiated, practitioners possess ability to gain recognition of issues not open to ordinary eyes. These initiated then become repositories of a peculiar kind of knowledge about the world and the 
nature of human being which may not be available to the public for general consumption. They are exposed to truths that are not open to ordinary people.

For Grotte (2016) and Ilesanmi (2004), however, and to mitigate the negative import of 'occultic', examples of occultic societies abound. Every field of human endeavor such as, Jewelry, Bricklaying, and even OM have propensity for developing the occult. For him, "As an example, any of us can look at a gemstone and admire its beauty and rarity. A trained jeweler may study the same stone and note certain characteristics that have been pointed out to him by his masters as having importance. So through the teacher sensitizing the student to become aware of factors formerly ignored, a realm that was formerly not invisible but always present, becomes accessible," (Grotte 2016: 01). Given this, in a more exoteric (Awoloalu 1979: 75) sense, someone is an occult member in a field if one is qualified, albeit by long years of training and or experience, to be exposed to some privileged rudiment of knowledge about that field which may not be readily available to non- members or the new starters.

Of course, so primary is the rule that without initiation, the core truths being searched for about the indigenous medicine may never be acquired. This rule is equally true of the OM. A consultancy level in OM is a classified realm to an ordinary people. Consultants, given the long years of training, are exposed to some classified and or privileged knowledge not available or unintelligible to ordinary people. Therefore, the process of consultancy in OM might be synonymous with a process of initiation in YIM. But, again, it is a strict injunction that once initiated, there is a limit to the truth about the medicine permitted to be revealed to the uninitiated and even to the world except on useful occasion. This might become imperative for two reasons. First, this is to preserve the core values of that restricted realm in particular, and the medicine in general from undesirable abuse which might have serious and fatal consequences. Second, the restriction might result from the fact that even the ordinary and uninitiated person might not understand such realities or knowledge when they are told. This might lead into misinterpretation and or misunderstanding and then an eventual misuse of the power.

A professionally trained heavy weight boxer is disallowed from public fight to avoid a misuse of training and professionalism. By the same token, the modus tollens rule of inference is unintelligible to a non-member of the learned occult. This, in essence, does not count as a minus for the YIM, it only underscores its strong efficacy and ensures it preservation. This is the reason it is described as homeopathic as Kola Abimbola argues, (Abimbola 2006: $78-79$ ), which enables it to ensure total and or holistic healing, (Samuel et'al 2014). Part of the truths which becomes known is that, contrary to some negative assumptions, YIM has its "metaphysical foundations in the nature of things" (Makinde, 1988: 92). It is instructive to note that from the foregoing, 
nothing suggests that YIM is unnatural. Everything about YIM is scientific and natural. The main problematic question is whether all natural and scientific is only empirical.

OM gained its acceptance and recognition because curious minds surrender themselves to being initiated into the cult of practitioners. In the same vein, and contrary to Borokini and Lawal's (2014: 31), curious minds are also always welcome and allowed, if they are willing and ready, to surrender themselves to the initiation into the cult of the YIM, (Ilesanmi 2004: 9). This shall avail their certification for the study of the YIM and becoming experts and consultants in it. In fact, as it has always been called, it is when curious and willing individuals surrender themselves to the study that they might begin the modernization of the phenomenon; whatever 'modernization' shall eventually mean in that realm. YIM knowledge system is therefore a gray area; vast, unexplored and long neglected (Jeliffe \& Bennet, 1960; Abbas \& Broadhead, 1997; Jenkins, 1997). This is a call for support in productive researches to divulge the secrets, (if it is indeed secret) of the alleged magical aspect of YIM. As identified by Samuel et al, (2014), lots of misconceptions about it is necessitated by "the lack of sufficient time and research funds to showcase its potentials", (Samuel et al 2014: 51). This, of course, is a reasonable call rather than a wishful condemnation.

What this concludes is that, more often than not, YIM has been misunderstood, and misjudged. Objectivity, verification, evidence, investigation, correspondence, and etc... are all the concepts used to underline western science. But, all these are accepted as mere conventions. These concepts could also be true under a different conventional interpretation. As Thomson argues, "The African is a victim of misrepresentation and obloquy in the hands of foreign travelers not because he has nothing to offer but because, in most cases, he is careless in the manner of presentation of his culture and tradition," (Thompson 1977: 264).Although no one takes the blame for or encourages carelessness, the main point which is encapsulated is that civilization and modernization "is not an exclusive preserve of Europe or America", (Thompson 1977: 264). Rather, philosophical thinking is in the minds of people, whether black or white. It is a prerogative of every individual, and culture. The African method (Maclean 1974), which may be Ifá divination, may vary from the western method of philosophy, (Ogunleye, 2015: 101). It is not impossible to find variation in methodology, what is important is similarity in result.

Where it is efficacious and significant, some sorts of the so-called magical beliefs are still held by some industrialized countries. An example of this is found in Martin Hill's (2009:37) recommendation of traditional medicine and healing for the aboriginal people of Canada. "So, it would be wrong to attribute magical, irrational, and superstitious ideas to any group of countries 
or level of industrial or educational development," (Sofowora 1993: 27 -28). The point is that it becomes unjustified to condemn YIM as magical because it fails the test of empirical science; the test that empirical science itself does not pass. The untenable vogue is that any worldview or phenomenon which fails the test of empirical justification is magical or irrational. By this requirement, $\mathrm{OM}$ is also magical and unintelligible. Therefore, it lacks a stand to declare YIM unjustified. In matters of efficacy, OM and YIM rise together, whereas in matters of empirical justification they both fall.

\section{Conclusion}

This study concludes that the charge that the fundamentals of YIM is not justified because it is not empirically verifiable, is also true of science. Empirical science, at its core, is bereft of empirical justification. Therefore, if YIM is magical because its core is not open to empirical verification then so is OM. However, if OM is also justified by its efficacious evidences, so is YIM. What this established is that while OM enjoys rigorous research which explains its development and acceptance, YIM is abandoned and perhaps condemned. The paper makes a call for support in rigorous research into the YIM since what is referred to as magical is eventually natural. The paper then concludes that OM lacks any sufficient ground to declare YIM as unjustified. This is because in matters of efficacy, both OM and YIM rise together. But, in matters of empirical justification, they also fall.

- Acknowledgment: The useful comments and relevant materials from Drs. Oladosu and Badejo, of Departments of Religious Studies, and Philosophy respectively, both at Obafemi Awolowo University, Ile-Ife, Nigeria, strengthen the paper. Many thanks.

\section{Bibliography}

Abas, M. A., \& Broadhead, J. C. "Depression and Anxiety among Women in an Urban Setting in Zimbabwe." Psychological Medicine, 27, (1997): 59-71. Abdulahi, A. A. "Trends and Challenges of Traditional Medicine in Africa". African Journal of Traditional, Complementary and Alternative Medicine, (AJTCAM). 8, (5) (Suppl), (2011): 115 -23.

Abimbola, W. "Ifa as a Body of Knowledge and as an Academic Discipline". Journal of Culture and Ideas. 1 (1) (1983): 1.

Abimbola, K. Yoruba Culture: A Philosophical Account. London: Iroko Academy Publishers, 2006. 
Adekola, O. O. Textual Divination among the Yoruba of Nigeria, A Comparative Study of Ifa and Yanrin in Ibadan. Unpublished Ph.D Thesis. Ibadan: University of Ibadan, 1998.

Awojodu, O and Baran, D. "Traditional Yoruba Medicine in Nigeria: A Comparative Approach". Bulletin of the Transilvania University of Brasov. Vol. 6(51) (2009): $129-36$.

Awolalu, J. O. Yoruba Beliefs and Sacrificial Rites. Essex: Longman Group Limited, 1979.

Borokini, T. I. and Lawal, I. O. "Traditional Medicine Practices among the Yoruba People of Nigeria: A historical Perspective". Journal of Medicinal Plants Studies. 2(6), (2014): 20 -33.

Buechner, J. Godel Putnam, and Functionalism: A New Reading of Representation and Reality. London: MIT. 2008.

Descartes, R. Six Metaphysical Meditations Including Objections by Thomas Hobbes. Translated by William Molyneux. London: Benjamin Tooke, 1680. Flanagan, Owen. "Quinean Ethics." An International Journal of Social, Political, and Legal Philosophy, Volume 93 Number 1, (1982): 56 -74.

Grotte, L. B. Ifa Medicine of West Africa. Ohio: Lyndhurst 5399 Mayfield Road, 2016. http://www.drgrotte.com/AfricanMedicine.shtml. Accessed on 15 January, 2017. Hamlyn, D. W. The Theory of Knowledge. London: Macmillan Press Ltd, 1970.

Hill, M. D. "Traditional Medicine and Restoration of Wellness Strategies". Journal of Aboriginal Health: 5 (1) (2009): 26 -42.

Hospers, J. An Introduction to Philosophical Analysis; Revised Edition. London: Routledge and Kegan Paul Limited, 2009.

Hume, D. "Skeptical Doubts Concerning the Operation of the Understanding". In Nagel and Brandt. Meaning and Knowledge; Systematic Readings in Epistemology. New York: Brace and World, Inc., 1965Hume, D. An Enquiry Concerning Human Understanding. Harvard: Collier \& Son, 1910.

Ilesanmi, T. M. Yoruba Orature \& Literature: A Cultural Analysis. Ile-Ife: Obafemi Awolowo University Press Ltd, 2004.

Jegede, A. S. "The Yoruba Cultural Construction of Health and Illness". Nordic Journal of African Studies. 11(3) (2002): 322 -35.

Jegede, O. Incantations and Herbal Cures in Ifa Divination: Emerging Issues in Indigenous Knowledge. Ibadan: African Association for the Study of Religion, 2010.

Jegede, C. O. "The Indigenous Medical Knowledge Systems, Perceptions and Treatment of Mental Illness among the Yoruba of Nigeria." Studies in Sociology of Science. Vol 7 No 5 (2016).

Jeliffe, D. B., \& Bennet, F. J. Indigenous medical systems and child health. Journal of Paediatrics, 57(2), (1960): 248-61. 
Kant, I. Critique of Pure Reason, Translated by Norman Kemp Smith. London: Macmillan \& Company Limited, 1963.

Lambo, J. O. "The Healing Power of Herbs with Special Reference to Obstetrics and Gynaecology" African Medicinal Plants, Sofowora E. A. (ed), University of Ife Press, Ife, 1979.

Locke, J. An Essay Concerning Human Understanding. Pennsylvania: Pennsylvania State University, 1690Maclean, U. Magical Medicine: A Nigerian Case Study. London: Penguin Books, 1974.

Makinde, M. A. African Philosophy, Culture, and Traditional Medicine. Athens, Ohio University Press, 1988.

Africa Philosophy: The Demise of a Controversy. Ile-Ife: Obafemi Awolowo University Press Limited, 2007.

Mbiti, J. S. African Religions and Philosophy. London: Heinemann Books Ltd, 1969.

Oduyoye, M. C. "The Medicine Men, the Magician and the Wise Men". In Adegbola, G. A. Traditional Religion in West Africa, (ed). Ibadan: Daystar Press, 1983.

Ogunleye, A. R. "Omotade Adegbindin; 2014; "Ifa in Yoruba Thought System". African Studies Quarterly, Vol. 16, Issue 1 (2015): 101 -03.

Olson, J and Nkiwane, S. Integrate for Efficiency: Yoruba Medicine in Nigeria, 2006. m.coloradocollege.edu/dotAsset/le11b094-e138-4a36-blae609d0c124538. Accessed on 26-12-2017.

Oyelakin, R. T. "Yoruba Traditional Medicine and the Challenge of Integration." Journal of Pan African Studies, Vol. 3 No 3 (2009): 73 -90.

Parrinder, E. G. West African Religion. London: Epworth Press, 1949.

Rodney, W. How Europe Underdeveloped Africa. London: Bogle-L'Ouverture Publications, 1976.

Samuel S. Antwi-Baffour, Ajediran I. Bello, David N. Adjei, Seidu A. Mahmood, Patrick F. Ayeh-Kumi. "The Place of Traditional Medicine in the African Society: The Science, Acceptance and Support", American Journal of Health Research. Vol. 2, No. 2, (2014): 49 -54. doi: 10.11648/j. ajhr.20140202.13.

Sofowora, A. Medicinal Plants and Traditional Medicine in Africa. Ibadan: Spectrum Books Limited, 1993.

Thompson, J. A. African Science: Belief or Superstition? Ibadan: Newton House Publication, 1977.

Wood, A. W. Basic Writings of Kant. New York: Modern Library; The random House Publishing Group, 2001. 